\title{
Lost in a Plethora of Concerns? Match, Mismatch and Hypnotism: The Case of the New Zealand Public Sector
}

\author{
Bikram Chatterjee ${ }^{1}$ \\ School of Accounting and Computer Science \\ Charles Sturt University \\ Panorama Avenue \\ Bathurst, NSW 2795 \\ Ph: +612 63384427 \\ Fax: +612 63384649 \\ e-mail: bchatter@csu.edu.au \\ Soheila Mirshekary \\ School of Commerce \\ Faculty of Business and Informatics \\ Central Queensland University \\ e-mail: $\underline{\text { s.mirshekary@cqu.edu.au }}$
}

\begin{abstract}
The paper is centred on the theme that the significance attached to attaining higher 'efficiency' standards in monetary/ numeric terms to attain better 'economy' in New Zealand may have led to a change in concept of 'ethics.' This is due to higher stress attached during the New Zealand public sector reform to attaining higher efficiency and economic supremacy compared to before the reform. Again, an endeavour to attain economic supremacy at the macro level does not lead to attaining higher efficiency standards at the specific organisational levels and vice versa. The authors suggest that the hypnotic state of the authors has been brought by a dearth of research in regard to the match/mismatch of these three Es, that is, economy, efficiency and ethics. Following this hypnotic state of authors' future research is suggested in regard to the conceptual schema of existence of these three Es in New Zealand public sector.
\end{abstract}

Keywords: Public Sector Reform; New Zealand; Economy; Efficiency; Ethics; Match; Mismatch

\section{Introduction}

Being lost in a complex world of matches leading to mismatches, may lead to structural hypnotism that serves its own purposes. Hypnotists on their stage performance have shown incredible results starting from participants performing dramatic acts, such as, reciting poetry forgotten by them in the distant past and barking like a puppy. However, hypnotic techniques have not been restricted to performing on the stage and providing entertainment to audiences. Hypnotic techniques have also been adopted in various organisations in conjunction with various other techniques such as NLP (neuro linguistic programming) and Time Line Therapy (Chetwynd, 2003). In accordance with hypnotist Paul McKenna, hypnotic techniques help individuals to be influential and persuasive (Chetwynd, 2003). This paper considers the persuasive and influential effect of hypnotism and provides evidence that hypnotism may be a

\footnotetext{
${ }^{1}$ Corresponding author. He was previously an Assistant Lecturer and Tutor at Massey University, New Zealand. He is now a lecturer at Charles Sturt University, Australia.

The views expressed in this article are those of the authors. The authors would like to acknowledge the contribution made by Ms Mary Rossiter, School of Accountancy, Massey University for editing this paper. The authors would also like to acknowledge the valuable comments provided by two anonymous reviewers, which helped in improving the earlier version of this paper.
} 
way to overcome inherent complex problems. The paper does not indicate that such hypnotism was created during the New Zealand public sector reform process and leaves its genesis as an issue for future researchers to explore.

We take a closer look at events and trends encompassing New Zealand public sector reform, taking three key attributes that has been the centre of attention by the government during the reform process, that is, ethics, economy and efficiency over time. In regard to public sector, ethics can be considered as a form of self-accountability of public sector employees (Rosbloom, 1993) while 'economy' refers to "the wealth and resources of a community" (Tulloch 1997, p.466) that can be created by 'economy of scale' or 'economy of scope' or a conjunction of both. 'Economy of scale' can be attained through achieving higher efficiency in terms of operation resulting in a reduction of cost per unit due to increased production (Singer, 2004) and 'economy of scope' refers to attaining cost savings as a result of scope, such as combining two or more product lines in a firm rather than producing them separately (Panzar and Willlig, 1981). 'Efficiency' refers to "the state or quality of being efficient" (Tulloch 1997, p.469). 'Efficient' refers to "productive with minimum waste or effort" (Tulloch 1997, p.469). 'Efficiency' is generally judged by comparing the result with the benchmark, which provides a relative measure of efficiency (Bozec, Dia and Breton, 2006).

Following these definitions, economy can be achieved by being efficient but may result in a threat to ethics or a change in an ethical climate. However, it is our expectation that an ethical climate was not negotiated in the New Zealand public sector even though the situation stressed economy and efficiency. This led us to a state of hypnotism resulting from a dearth of literature as to how this match was achieved. The paper provides a discussion of events by following previous literature, leading to a discussion of the state of hypnotism, which may equally be applicable to the readers of our article. Future research is suggested that should take us out of this hypnotic state.

\section{The Plethora of Events: Event Mis/Management}

Major reforms took place in the New Zealand public sector following a fiscal deficit in 1984 (Kettl 1997; Schwartz 1997) leading to a reorganisation of the country's institutional and ideological structure (Schwartz 1994). The reorganisation led to corporatisation and commercialisation of public sector entities as well as outsourcing (Gill 2001). The ideology behind the reform was the pursuit of taxpayers' money by enhancing the management efficiency of public sector entities in line with that of the private sector (Funnell 2004). The principle reason behind such reorganisation, more widely termed as 'reform' was the poor performance of the New Zealand public sector in 1970s and 1980s (Campos and Pradhan 1997). The sector started to concentrate on overcoming the fiscal deficit by enhancing technical efficiency, establishing transparency of their operational results, and being accountable to the public for those results (Campos and Pradhan 1997).

“Transparency' refers to availability of an organisation's information to those external to it (Bushman, Piotroski and Smith, 2004). On the other hand, 'accountability' is an external check on public administrators (Rosbloom, 1993). Accountability can be best achieved by aligning the same mechanisms employed to measure transparency and then taking those mechanisms further to analyse whether the agent has attained the required target, so that a perfect match is obtained between 'transparency' and 'accountability.' This match also saves us from employing different techniques to achieve these two inter-related aims. 
Transparency has been laid down in the New Zealand public sector through: the specification of outputs in contracts made between government entities and their Chief Executives (CEs); appropriations, taking outputs purchased by the government as the basis; the requirement to prepare and publish financial statements showing net worth of the government and legislatively enforced frequent disclosure of performance information (Campos and Pradhan 1997). In the New Zealand public sector, accountability was enforced through: employing agency heads on a tenure basis rather than on a permanent one, which was the practice before the reform; proper specification of outputs expected from organisations; the administration of implicit and explicit employment contracts for agency heads and their employees; and the requirement to publish accounts and carry on audit trials of such accounts. The New Zealand public sector has based its priority on technical efficiency rather than on strategic priority setting. This has resulted in an emphasis on the provision of technical efficiency in the delivery of outputs, such as goods and services produced, rather than an emphasis on outcomes (impact of such outputs) (Campos and Pradhan 1997).

The emphasis on technical efficiency in daily operations and reporting in the public sector, through the introduction of a requirement to publish annual financial accounts is not surprising as employing the same mechanism to fulfil transparency and accountability is expected to provide perfect match in regard to the technicality involved in the matter and saves cost of preparing two sets of data. However, external stakeholders demanding transparency from public sector entities and those demanding accountability may differ from each other, which we leave for future exploration. There has been a perfect match between the introduction of a market and competition in the New Zealand public sector (Wistrich 1992a) and emphasis on technical efficiency, a logical flow-on effect from the introduction of free market-like mechanism. The private sector thrives on profit and hence has had to establish technical efficiency to various stakeholders. However, the public sector, specifically the notfor-profit public sector, does not thrive on profit. Hence the application of technical efficiency in the public sector can be interpreted as a mismatch taking the goal of profit-making into consideration but matches with the notion of competition as applied in the private sector. This does not mean that private sector techniques are not applicable to the public sector, but it leaves the match or mismatch open for exploration. If this concern ended our paper we would be happy to go no further and conduct a study in this area. However, the concern of match/mismatch does not end here. It goes further at the level of policy making, and this is explained next.

The reform stresses efficient management of services through the introduction of systems designed to provide freedom from political intervention to managers, while setting politically determined objectives at the policy level and establishing transparent reporting procedures. Ministers determine policy objectives and they are accountable to Parliament for 'outcomes,' that is, for attaining intended objectives, while CEs are responsible for attaining 'outputs' as efficiently as possible (Wistrich 1992b). This approach to governance confuses the authors in regard to the manner in which transparency and accountability at the macro level matches that of micro level (at individual organisational level). It suggests that fulfilment of outputs leads to fulfilment of outcome, which can be a truth but leaves ground for future exploration. Again, in regard to transparency and hence accountability at the individual level we might find a complete match between expected outputs and actual outputs for all organisations which might make us believe that the same has been fulfilled at the macro level. So, the confusion rests upon where to start: the macro or micro level. Individual organisations may be technically efficient but whether the attainment of such technical efficiency leads to attaining subjective efficiency (outcomes) at the macro level is a question that still needs to be explored. 
Accountability and its inter-related transparency mechanisms have been imposed on public sector entities to justify the tax-payers that they are getting value for money (Funnell 2004). This approach is perceived to be hypnotism due to the fact that establishing efficiency by following the taxpayers' value-for-money doctrine is more complex and encompasses various other factors that are qualitative in nature. Taxpayers' value-for-money doctrine cannot be justified by merely mirroring the performance of individual public sector entities in monetary terms. Also, mere concentration of monetary/numeric data does not justify the rationale behind the existence of public sector entities in the market. This concern is commensurate with the concern stated above in regard to the macro and micro level debate.

It has been believed by Ministers in New Zealand that 'transparency' will eradicate unnecessary functions, develop efficient processes and clarify accountabilities (Meehan 1996). Agencies attaining high rates of return and low costs for services are provided with more resources as they are rewarded through bigger contracts compared to agencies with low rates of return (Schwartz 1994). This raises doubt in regard to how unnecessary functions are determined. Functions are expected to be necessary when they provide high return. However, there may be numerous functions in the public sector or in public sector entities that have low rates of return due to their limited usage but may not be unnecessary to those who require those services. Economic rationality and technical efficiency cannot justify necessity in this scenario. We expect a different framework justifying the survival of sparingly used necessary services offered by various public sector entities, and this can be left for exploration.

The above section provides the plethora of events that has led us researchers to confusion and hence to the stage of hypnotism, as we are trying to believe that all linkages and events match each other providing tax-payers with value for money. In the following section an in-depth discussion and critical analysis of how these concepts are implemented in New Zealand public sector is given.

Under the new approach to governance, the Government specified a limited number of principally desired results for the public service as a whole over a period of three years. These are known as "strategic result areas" (SRAs) (Boston and Pallot 1997, p.383). More specific targets, known as "Key result areas" (KRAs) are formulated by taking SRAs as the basis for CEs of government departments (Boston and Pallot 1997). However, these SRAs and KRAs were not clearly defined (Boston and Pallot 1997). This lack of definition is as expected, as following non-numeric outcomes to numeric outputs is at best acceptable in a hypnotic state of mind and in a state of uncertainty.

Further concerns arise when we consider public sector ethics in this scenario of contracting, outputs and outcomes. Outputs and outcomes can be taken as a representation of the terms 'efficiency' and 'economy' respectively. The introduction of contracts in the public sector following this emphasis on 'outputs,' 'outcomes,' 'economy' and 'efficiency' has led to a reduction in the traditional values of public service, personal responsibility and professionalism (Schick 1998). The contacts have led to a checklist approach to accountability of managers (Schick 1998), but their effect on ethics has not been investigated until now. We do not intend to comment that a checklist approach is detrimental to the country. The five fruits a day approach for a healthier life is also a checklist, which is good for the human body. However, though water is good for human body twenty litres of water a day may be excessive. Hence the question arises as to whether this checklist is in the range of five fruits or twenty litres of water. It may well be the fact that this checklist approach is in line with the traditional informal values of the public sector and may have not changed the value culture of 
the sector, while the contrary is possible as well. This could be an interesting topic of investigation.

Another topic which arises following the emphasis on 'economy' and 'efficiency' in New Zealand public sector is 'ethics.' Following this state of mind, how do the three Es, that is, economy, efficiency and ethics, complements each other or is it a state of compromise. This starts from the state of our mind as to the meaning of ethics and our perception of ethics. Studies exploring the ethical climate in New Zealand/Australian public sector are sparse. The existing studies suggest that the development of a formal code of ethics in the public sector requires the balancing of ethical values on the one hand and a corporate managerialist framework which uses performance indicators on the other hand (Haynes and Jones 1999). This does not itself mean that in our hypnotised state the whole choreography disrupts our state of mind. It may well be possible to adapt the private sector ethical climate to that of the public sector philosophy of serving society. However, whether this match has been achieved is a question that needs to be explored.

Harris (1999) criticises the contractual mechanism in the public sector by stating that students in public schools and patients in hospitals are not customers. Their treatment by the public service cannot be equated with private sector treatments, as the public sector does not exist for profit. This opinion may not have to be believed in the organic sense as we may be in an era of contractual ethics that needs further exploration.

Gregory and Hicks (1999) state that the imposition of 'managerialism' in the public sector in line with that of the private sector, as has been done in New Zealand, may threaten the ethical probity in the public sector as lower incentives are provided in business entities to stop corruption. The authors advise an organic interpretation of public administration, rather than a narrow mechanistic one. Otherwise high standards of honesty, integrity and fairness in public sector governance in countries such as New Zealand may be at risk.

It is our perception that a narrow mechanistic approach may lead to a lower standard of integrity and fairness as, in this new era, fairness is perceived to be judged with a mechanistic approach which may be termed 'mechanical fairness/ mechanical integrity.' Hence, the question that needs to be explored here is whether the perception of 'fairness/ integrity' has itself changed since these new mechanisms were implemented. Following on from this research is needed to explore the conceptual foundation of fairness and integrity.

\section{Ethics in The Public Sector- Previous Studies}

There are few studies concentrating on the ethical climate in the public sector and hence, our state of hypnotism remains. However, the existing studies are discussed below:

Ashkanasy, Falkus and Callan (2000) investigated the ethical attitudes of public sector employees in Australia. The authors state that demographic variables (gender, managerial level and job tenure) and personal ethical values together with contextual (conflict between personal values and work demands, relevance of a formal code of conduct as perceived by individuals and perceived requirement for a formal code of conduct) and group-level variables (extent of use of code of conduct by an individual's work group) were related to dependent variables, consisting of the use of code or ethical tolerance. However, the organisation's reward scheme had no relationship with the use of an ethical code or ethical tolerance. Following these results, the authors suggest that the use of an ethical code in an organisation is a self-perpetuating one, that is, if a majority of employees in an organisation use the code, it is more likely that other individuals will also follow the code. This study does not elaborate 
on the ethical climate in the public sector or whether the status of 'ethics' itself has changed due to a shift following the imposition of managerialism and the value-for-money ethos similar to that of private sector.

The concern that ethics has been compromised to address financial targets in the Australian public sector has been raised by Haynes and Jones (1999). Haynes and Jones (1999) suggest that the principle concerns while developing a code of ethics in the public sector result from balancing demands of two contesting natures, that is, ethical values on one hand and a corporate managerialist framework which uses performance indicators on the other hand. These authors suggest that contestability, philosophical integrity, performance indicators and whistle blowers' protection are key elements that need to be considered in developing a code of ethics in business-like public entities, such as those existing in Australia. The same concern is applicable in New Zealand public sector as well.

James (2003) addressed the issue of attaining 'economic rationalism' in public administration and its impacts on the decisions made by public sector organisations. The motivation to attain common good, as distinct from personal interest has less recognition in the economic rationalist paradigm. This raises further concern in regard to the ethical climate in public sector entities. A similar concern has been shown by Harris (1999). Harris (1999) discussed the ethical impact of placing public sector employees on contracts which give employers the power to dispose of employees without giving a reason and further do not allow appeals from employees. Previously, the public sector used to provide benefits to its employees, which provided a motivation to public sector employees to act ethically or professionally. At present such benefits do not exist, as public sector principles of pragmatism and ethics have been replaced by outcomes. Hence, the attainment of high ethical standards may not be a priority and hence these standards may be at risk.

\section{The Art of Hypnotism}

The art of hypnotism involves making a subject act on external suggestion (Tulloch 1997). The art of hypnotism can be aligned with the term 'rhetoric,' which is a widely used term meaning an expression that appears to be true. Some of the private-sector entities in Australia, France, Germany, the Netherlands, the United Kingdom (U.K.), and the United States (U.S.) were found to provide graphs on selective areas and distorted graphs in their annual reports that gave more positive depiction than the actual one (Beattie and Jones 2000). Similarly, observation of financial graphs of 250 U.K. companies revealed that these companies were disclosing graphs with slopes different from the optimum, that is, 45 degrees, in order to create a more positive impression than the actual one (Beattie and Jones 2002).

Similarly, New Zealand public sector is concentrating on financial aspects to establish their operational supremacy, which is represented by 'economy' and 'efficiency.' However, another significant aspect of the public sector is the provision of services as the public sector does not solely exist to make profit. 'Ethics' plays a dominating role in the quality of service provision.

Studies on the ethical climate of public sector entities are sparse, and there have been no studies observing the ethical climate at present when the supremacy of an operation is measured from financial perspectives rather than quality of service. We are hypnotised by financial criteria to judge the supremacy of the operation of public sector entities and hence we often are concerned about value-for-money. In this hypnotised state we believe that the three Es (economy, efficiency and ethics) can exist side-by-side without negotiation or 
compromise. However, if we were to come out of this hypnotised state, serious doubt would be raised about the compromises that have taken place.

\section{Conclusion: The Proposed Way Out}

Hypnotism, to the authors, is an art which makes us believe what we see is the state of reality notwithstanding any abnormality. We can believe in the fact that these three Es match and can live together in this state of mind. However, coming out of that state triggers questions such as whether these three Es can be co-existent. It may well be the fact that they can be co-existent while the contrary may be true as well. A perfect match may have been obtained, with a change in the concepts of 'economy,' 'efficiency' and 'ethics,' in the public sector. Any future research needs to address these conceptual foundations first before commenting on whether the present state is a compromise or a perfect state of match, wherein concerns have been divulged in the wave of compromise.

Another question arising out of this reform is the relationship between economy and efficiency. Attaining economic supremacy may well lead to efficiency in regard to service provision and technical efficiency may lead to economic supremacy. This will be a perfect state wherein we, as authors, get lost in regard to the linkages and relationships leading us to believe in the state of hypnotism, in the absence of any evidence to the contrary. However, there exists considerable doubt in regard to their mutual fulfilment when public sector is considered, which does not exist for making profit. This is due to the fact that efficient operation is mainly sought by economists or those associated closely with economy but not by social managers. Social managers are more interested in welfare of individuals and groups (James, 2007). Hence, the expectation of mutual fulfilment of economy and efficiency in New Zealand public sector needs to be further explored.

The significance of this paper can be further stressed due to the fact that ethics is expected to have a role in economics. Ethical behaviour in a society is expected to enhance efficiency of an economy (Businessline, 1999). On the other hand, we believe that the perception of 'ethics' is expected to differ from that which existed before the New Zealand public sector reform. This is due to higher stress attached to attaining higher efficiency and economic supremacy during this reform. Again, attaining economic supremacy at the macro level does not necessarily refer to the fact that public sector entities have gained higher efficiency standards. This is due to the fact that 'efficiency' is a relative concept and cannot be solely judged from numerical terms. Following our concerns, we conclude that the scope of future research is wide and needs to be based on conceptual schemas. We leave it to future researchers to take us out of this state of hypnotism through empirical validation and experiments. Until then we will believe in the present state of match as expected in the reform process. Exploring these three Es and their present state and relationships, together with carryon-effects is expected to be an interesting thesis.

\section{References:}

Ashkanasy, N.M., Falkus, S., \& Callan, V.J 2000, 'Predictors of Ethical Code Use and Ethical Tolerance in the Public Sector,' Journal of Business Ethics, vol. 25, pp. 237-253.

Beattie, V., \& Jones, M. 2000, 'Impression Management: The case of Inter-country financial graphs,' Journal of International Accounting, Auditing \& Taxation, vol. 9 no. 2, 159-183.

Beattie, V., \& Jones, M. 2002, 'The impact of graph slope on rate of change judgements in corporate reports,' ABACUS, vol. 38 no.2, 177-199.

Boston, J \& Pallot, J 1997, 'Linking Strategy and Performance: Developments in the New Zealand Public Sector', Journal of Policy Analysis and Management, vol. 14, no. 3, pp. 382-404. 
Bozec, R., Dia, M. \& Breton, G 2006, 'Ownership-efficiency relationship and the measurement selection bias,' Accounting and Finance, vol. 46, 733-754.

Bushman, R.M., Piotroski, J.D \& Smith, A.J 2004, What determines corporate transparency?, Journal of Accounting Research, vol. 42, no.2, pp.207-252.

Businessline 1999, 'The four-angled approach,' August.

Campos, JE \& Pradhan, S 1997, 'Evaluating Public Expenditure Management Systems: An Experimental Methodology with an Application to the Australia and New Zealand Reforms', Journal of Policy Analysis and Management, vol. 16, no. 3, pp. 423-445.

Chetwynd, C (2003), 'Hypnosis: Whacy but it works for the bottom line,' Accounting \& Business, April, pp.3435.

Funnell, W 2004, 'Further evidence on the roots of public sector operational (value-for-money) auditing: a response to Flesher and Zarzeski,' Accounting and Business Research, vol. 34, no. 3, pp. 215-222.

Gill, J 2001, 'Some New Zealand public sector outsourcing experiences,' Journal of Change Management, vol. 1 , no. 3, 280-291.

Gregory, R \& Hicks, C 1999, 'Promoting Public Service Integrity: A Case for Responsible Accountability', Australian Journal of Public Administration, vol. 58, no. 4, pp. 3-15.

Harris, T 1999, 'Competition, Marketisation, Public Services and Public Ethics', Australian Journal of Public Administration, vol. 58, no. 4, pp. 32-38.

Haynes, B \& Jones, HM 1999, 'Ethics and Public Sector Management: The Western Australian Experience', Australian Journal of Public Administration, vol. 58, no. 2, pp. 70-82.

James, C 2003, 'Economic Rationalism and Public Sector Ethics: Conflicts and Catalysts', Australian Journal of Public Administration, vol. 62, no. 1, pp. 95-108.

James, C 2007, 'Defining key differences,' Management, February, p.22.

Kettl, DF 1997, 'The Global Revolution in Public Management: Driving Themes, Missing Links', Journal of Policy Analysis and Management, vol. 16, no. 3, pp. 446-462.

Meehan, H 1996, 'The development of government information management policies in New Zealand through a period of reform,' Government information Quarterly, vol. 13, no. 3, pp. 232-244.

Panzar, JC, Willig, RD 1981, 'Sustainability Analysis: Economies of Scope,' AEA Papers and Proceedings, vol. 71, no.2, pp. 268-272.

Rosbloom, 1993, 'Accountability and Ethics,' In Public Administration (3 ${ }^{\text {rd }}$ Ed.).

Schick, A 1998, 'Why Most Developing Countries Should Not Try New Zealand's Reforms', The World Bank Research Observer, vol. 13, no. 1, pp. 123-131.

Schwartz, HM 1994, 'Public Sector Theory and Public Choices: Bureaucrats and State Reorganization in Australia, Denmark, New Zealand and Sweden in the 1980s', Administration \& Society, vol. 26, no. 1, pp. $48-77$.

Schwartz, HM 1997, 'Reinvention and Retrenchment: Lessons from the Application of New Zealand Model to Alberta, Canada', Journal of Policy Analysis and Management, vol. 16, no. 3, pp. 405-422.

Singer, P 2004, 'In the materials age, what happens to economy of scale?,' Semiconductor, p.17.

Tulloch, S (ed.). 1997. Oxford Dictionary and Thesaurus, Melbourne: Oxford University Press. 
Wistrich, E 1992a, 'Managing sub-national government in New Zealand', Public money \& management, vol. 12, no. 4, pp. 25-29.

Wistrich, E 1992b, 'Restructuring Government New Zealand Style', Public Administration, vol. 70, no. 1, pp. 119-135. 